\title{
PENGEMBANGAN DASHBOARD KONTROL PENGENDALIAN MUTU PADA BAGIAN PRINTING DAN EMBOSS PT. MEGAH MAS PRIMA
}

\author{
Arief Herdiansah $^{1}$, Rosdiana $^{2}$, Febriana Wulandani $^{3}$ \\ Dosen Universitas Muhammadiyah Tangerang ${ }^{1}$, Dosen Universitas Raharja ${ }^{2}$, \\ Staf QC PT. Megah Mas Prima ${ }^{3}$ \\ Jl. Perintis Kemerdekaan I Babakan No.33, Kota Tangerang ${ }^{1}$, \\ Jl. Jenderal Sudirman No.40, Cikokol, Kota Tangerang ${ }^{2}$ \\ Jl. Mohammad Toha KM. 4.7, Periuk, Kota Tangerang ${ }^{3}$ \\ Sur-el : arief_herdiansah@ umt.ac.id ${ }^{1}$, ros@ raharja.info ${ }^{2}$, qc2@megahmas.co.id ${ }^{2}$
}

\begin{abstract}
Quality control of production is an important thing that must be done by manufacturing companies to be able to produce products in accordance with customer orders. Quality Control $(Q C)$ is the department that is responsible for maintaining the quality of the products produced in accordance with predetermined standards. This research was conducted at PT Megah Mas Prima, currently the company still uses conventional methods in the process of creating reports on the results of printing and embossed production. The process of entering the recapitulation data of $Q C$ results using Microsoft Excel application, this is very difficult for QC staff because there are many criteria and material codes that must be entered so that the process of making reports requires quite a long time and the level of human error is also high. This research has produced an information system that can assist quality control staff in entering QC data, create QC reporting and accelerate the process of delivering data to QC managers and to other parties who need it.
\end{abstract}

Keywords: Quality Control, Production Result, Reporting, Manufacturing.

\begin{abstract}
Abstrak : Pengendalian mutu hasil produksi merupakan hal penting yang wajib dilakukan oleh perusahaan industri (pabrik) untuk dapat menghasilkan produk yang sesuai dengan pesanan pelanggan. Bagian Quality Control (QC) merupakan bagian yang bertanggung jawab untuk menjaga agar produk yang dihasilkan memiliki mutu sesuai dengan standar yang telah ditentukan. Penelitian ini dilakukan di PT Megah Mas Prima, saat ini perusahaan masih menggunakan metode konvensional dalam proses pembuatan laporan hasil produksi printing dan emboss. Proses pemasukan data rekapitulasi hasil QC menggunakan aplikasi Microsoft excel, hal ini sangat menyulitkan staf QC karena banyak kriteria dan kode material yang harus dimasukan sehingga proses pembuatan laporan membutuhkan waktu yang cukup lama dan tingkat kesalahan manusia juga tinggi. Penelitian ini telah menghasilkan sebuah sistem informasi yang dapat membantu staf quality control dalam memasukan data QC, membuat pelaporan QC serta mempercepat proses penyampaian data ke manajer QC dan kebagian lain yang membutuhkan.
\end{abstract}

Kata kunci: Pengendalian Mutu, Hasil Produksi, Laporan, Pabrik

\section{PENDAHULUAN}

Perkembangan teknologi informasi bidang industri membuat perusahaan berlomba-lomba memanfaatkanya untuk dapat meningkatkan efisiensi dan efektifitas proses produksi sehingga dapat menghasilkan suatu produk yang sesuai pesanan pelanggan. Penelitian ini dilakukan di PT Megah Mas Prima yang merupakan salah satu perusahaan yang bergerak dibidang industri sepatu, khususnya produksi pembuatan accessories sepatu. Dalam menjalankan proses produksi, PT Megah Mas Prima harus dapat melakukan pengendalian mutu kualitas produk yang dihasilkan. Proses pengendalian mutu hasil 
produksi dilakukan pada bagian pengendalian mutu atau bagian QC.

Kualitas adalah keseluruhan sifat suatu produk atau pelayanan yang berpengaruh pada kemampuannya untuk memuaskan kebutuhan yang dinyatakan atau tersirat [1]. QC merupakan bagian terpenting dalam sebuah rantai produksi, khususnya dalam hal pengendalian mutu kualitas produk yang dihasilkan perusahaan agar sesuai dengan standar kualitas produk sesuai pesanan pelanggan.

Pengendalian kualitas adalah teknik dan aktivitas operasional yang digunakan untuk memenuhi standar kualitas yang diharapkan [2]. Untuk menjaga kualitas produk yang dihasilkan diperlukan sistem informasi QC, yaitu sebuah sistem sebagai suatu himpunan dari berbagai bagian atau elemen, yang saling berhubungan secara teroganisasi berdasar fungsi-fungsinya, menjadi satu kesatuan [3]. Informasi adalah data yang diolah menjadi bentuk yang berguna untuk membuat keputusan karena informasi menurunkan ketidakpastian dan meningkatkan pengetahuan [4]. Sistem informasi merupakan disiplin yang belum sepenuhnya mapan seperti matematikan dan ekonomi. Sangat diperlukan pengetahuan dan pemahaman tentang ruang lingkup kajian bidang sistem informasi [5].

Saat ini proses pembuatan laporan QC di PT Megah Mas Prima masih dikerjakan secara konvensional, dimana proses pencatatan dilakukan dengan pencatatan manual (tulis tangan) menggunakan buku besar, catatan tersebut lalu diserahkan kepada staf QC, kemudian staf QC meng-input data tersebut ke dalam komputer menggunakan aplikasi MS excel, untuk kemudian membuat beberapa macam laporan sesuai dengan kebutuhan pimpinan perusahaan. Dalam melakukan proses pemasukan data QC hasil produksi, staf QC harus memasukan cukup banyak kriteria (part material), hal ini mengakibatkan sering terjadi kendala, yaitu terjadinya kekeliruan yang disebabkan salah dalam proses pemasukan data kriteria (part material) dan kendala waktu atau dibutuhkan waktu yang cukup lama bagi seorang staf QC dalam membuat beberapa laporan QC hasil produksi sesuai kebutuhan pimpinan perusahaan. Untuk membantu mempermudah dan mempercepat proses pemasukan data, pembuatan laporan dan penyampain laporan/data QC ke pimpinan perlu dikembangkan suatu sistem informasi QC berbasis web yang dapat memenuhi kebutuhan pemasukan data QC, memenuhi kebutuhan pembuatan laporan QC serta menghasilkan sebuah dashboard yang dapat dijadikan acuan pimpinan dalam mengambil sebuah keputusan.

Dashboard adalah alat penting untuk memonitor keadaan sehari-hari suatu organisasi dan sebagai alat penghubung tunggal yang digunakan untuk membuat keputusan dan mempuyai akses untuk mengunci indikator kinerja/KPI, dashboard seperti sebuah jaringan lokal yang eksekutif, dimana semua kegiatan ditampilkan [6]. Executive dashboard merupakan sebuah alat bantu berupa sistem informasi yang menampilkan informasi yang dapat dijadikan acuan manajemen untuk melakukan analisa aktifitas tim operasional dan untuk memprediksi data/hasil akkhir yang akan datang. executive dashboard merupakan sebuah 
alat bantu bagi majemen atau pimpinan perusahaan mengambil sebuah keputusan.

Dashboard memiliki beberapa kegunaan, yaitu:

1. Menampilkan informasi bisnis penting dalam bentuk tabel atau grafik pada sebuah tampilan/layar monitor, sehingga dapat mudah dilihat dan dipahami manajemen.

2. Dashboard menampilkan informasi yang dihasilkan data-data kegiatan perusahaan atau hasil produksi secara up to date.

3. Dapat dijadikan acuan dalam sebuah proses pengambilan keputusan yang cepat dan tepat oleh manajemen/pimpinan perusahaan.

\section{METODOLOGI PENELITIAN}

Metode penelitian yang digunakan dalam penelitian ini sebagai berikut:

\subsection{Metode Pemilihan Sample}

Metode pengambilan sample yang digunakan adalah purposive sampling yang merupakan teknik pengambilan sample dengan mengambil responden yang dipilih oleh peneliti menurut ciri-ciri spesifik yang dimiliki sample. Untuk penelitian ini responden merupakan orang yang terlibat dalam proses produksi dan pross pengendalian mutu/QC hasil produksi, agar peneliti memilik informasi detail berkaitan dengan barang hasil produksi dan proses QC yang dilakukan terhadap barang hasil produksi.

\subsection{Metode Pengumpulan Data}

Metode Pengumpulan data yang dijalankan dalam penelitian ini adalah:

1. Metode Survey dan Wawancara.

Peneliti telah melakukan kunjungan langsung ke tempat penelitian dan melakukan wawancara berkaitan dengan pengumpulan informasi aktifitas tim QC, kendala yang dihadapi dalam proses pengolahan data QC hasil printing dan emboss. Wawancara dilakukan kepada Section Head QC.

2. Metode Pustaka.

Peneliti membaca buku dan jurnal yang berkaitan dengan proses pembuatan sistem informasi khususnya pembangunan dashboard pengendalian mutu hasil produksi.

\subsection{Metode Analisa Sistem}

Proses analisa sistem yang peneliti gunakan adalah metode PIECES, metode ini digunakan karena dapat lebih detail menjabarkan permasalahan saat ini dan rencana pengembangan sistem untuk mengatasi permasalahan tersebut. Analisa metode PIECES meliputi analisa performance, information, economic, control, efficiency dan service. hasil analisa yang peneliti peroleh sebagai berikut.

a. Analisis Kinerja (Performance)

Tabel 1. Hasil Analisa Kinerja

\begin{tabular}{|c|c|c|}
\hline Parameter & $\begin{array}{c}\text { Sistem yang } \\
\text { Berjalan }\end{array}$ & $\begin{array}{c}\text { Sistem yang } \\
\text { Diusulkan }\end{array}$ \\
\hline $\begin{array}{l}\text { Trougho } \\
\text { ut }\end{array}$ & $\begin{array}{l}\text { Proses } \\
\text { pemasukan } \\
\text { data QC hasil } \\
\text { prouksi } \\
\text { dilakukan } \\
\text { menggunakan } \\
\text { aplikasi MS } \\
\text { excel dan } \\
\text { penyajian } \\
\text { laporan } \\
\text { diberikan } \\
\text { secara } \\
\text { langsung oleh } \\
\text { staf QC ke } \\
\text { pimpinan. }\end{array}$ & $\begin{array}{l}\text { Data kriteria } \\
\text { kriteria (part } \\
\text { material) disimpan } \\
\text { dalam database, } \\
\text { dan proses } \\
\text { pemasukan data } \\
\text { QC hasil produksi } \\
\text { dilakukan } \\
\text { menggunakan } \\
\text { sistem, pimpinan } \\
\text { dapat meminta } \\
\text { laporan ke staff } \\
\text { QC atau melihat } \\
\text { langsung melalui } \\
\text { sistem. }\end{array}$ \\
\hline
\end{tabular}




\begin{tabular}{lll} 
Respond & Dibutuhkan & Pemasukan data \\
Time & waktu yang & lebih cepat dan \\
& cukup lama & lebih akurat karena \\
untuk & mengunakan \\
& melakukan & master data part \\
proses & material yang \\
& pemasukan dan & disimpan dalam \\
memeriksa & database. \\
kebenaran data & \\
hasil QC yang & \\
di-entry & \\
\hline
\end{tabular}

b. Analisis Informasi (information)

Tabel 2. Hasil Analisa Informasi

\begin{tabular}{|c|c|c|}
\hline Parameter & $\begin{array}{c}\text { Sistem yang } \\
\text { Berjalan } \\
\end{array}$ & $\begin{array}{c}\text { Sistem yang } \\
\text { Diusulkan }\end{array}$ \\
\hline Akurat & $\begin{array}{l}\text { Kualitas } \\
\text { informasi yang } \\
\text { dihasilkan } \\
\text { terkadang kurang } \\
\text { akurat, karena } \\
\text { ada kesalahan } \\
\text { penulisan kriteria } \\
\text { (part material). }\end{array}$ & $\begin{array}{l}\text { Kualitas } \\
\text { informasi yang } \\
\text { dihasilkan lebih } \\
\text { akurat dan } \\
\text { kesalahan } \\
\text { penulisan } \\
\text { Kriteria (part } \\
\text { material) dapat } \\
\text { dihilangkan. }\end{array}$ \\
\hline Relevan & $\begin{array}{l}\text { Semua data yang } \\
\text { dimasukan staf } \\
\text { QC tertuang di } \\
\text { laporan, } \\
\text { sedangkan } \\
\text { kebutuhan } \\
\text { informasi } \\
\text { masing-masing } \\
\text { bagian berbeda. }\end{array}$ & $\begin{array}{l}\text { Laporan yang } \\
\text { dihasilkan dapat } \\
\text { disesuai dengan } \\
\text { kebutuhan } \\
\text { pengguna. }\end{array}$ \\
\hline $\begin{array}{l}\text { Tepat } \\
\text { waktu }\end{array}$ & $\begin{array}{l}\text { Penyampaian } \\
\text { laporan QC } \\
\text { terkadang tidak } \\
\text { tepat waktu. }\end{array}$ & $\begin{array}{l}\text { Laporan QC } \\
\text { dapat } \\
\text { disampaikan } \\
\text { tepat waktu. }\end{array}$ \\
\hline
\end{tabular}

c. Analisis Ekonomi (Economy)

Tabel 3. Hasil Analisa Ekonomi

\begin{tabular}{lll}
\hline Parameter & \multicolumn{1}{c}{$\begin{array}{c}\text { Sistem yang } \\
\text { Berjalan }\end{array}$} & $\begin{array}{c}\text { Sistem yang } \\
\text { Diusulkan }\end{array}$ \\
\hline Biaya & Saat "busy & Biaya lembur staf \\
& schedule" & QC pada saat \\
& perusahaan harus & "busy schedule" \\
& mengeluarkan & jauh berkurang. \\
biaya lembur staf. & \\
\hline
\end{tabular}

\section{d. Analisis Keamanan (Controling)}

Tabel 4. Hasil Analisa Keamanan Informasi

\begin{tabular}{lll}
\hline Parameter & $\begin{array}{c}\text { Sistem yang } \\
\text { Berjalan }\end{array}$ & \multicolumn{1}{c}{$\begin{array}{c}\text { Sistem yang } \\
\text { Diusulkan }\end{array}$} \\
\hline Kontrol & Tidak ada & Pengguna yang \\
Sistem & pengaturan & dapat mengkases \\
& keamanan & Informasi dan \\
\hline
\end{tabular}

\begin{tabular}{ll} 
informasi yang & sistem diatur \\
diterapkan & berdasarkan hak \\
karena proses & akses sesuai \\
akses terhadap & dengan tupoksi \\
informasi & (tugas pokok dan \\
dilakukan & fungsi) pengguna \\
dengan & tersebut. \\
konvensional. & \\
\hline
\end{tabular}

e. Analisis Efisiensi (Eficiency)

Tabel 5. Hasil Analisa Efisiensi

\begin{tabular}{lll}
\hline Parameter & $\begin{array}{c}\text { Sistem yang } \\
\text { Berjalan }\end{array}$ & \multicolumn{1}{c}{$\begin{array}{c}\text { Sistem yang } \\
\text { Diusulkan }\end{array}$} \\
\hline Sumber & Biaya tambahan & Biaya lembur \\
Biaya & terbesar yang & dapat ditekan \\
& dikeluarkan & semaksimal \\
& oleh perusahaan & mungkin, bahkan \\
& adalah & tidak tertutup \\
& membayar & kemungkinan \\
& biaya lembur & dihilangkan. \\
& staf QC. & \\
Tumber & Tenaga kerja & Tenaga kerja QC \\
Tenaga & QC berjumlah & berjumlah 2 \\
& 2. & dengan aktifitas \\
& & kerja yang lebih \\
& & efisien. \\
\hline
\end{tabular}

f. Layanan (Service)

Tabel 6. Hasil Analisa Layanan

\begin{tabular}{lll}
\hline Parameter & $\begin{array}{c}\text { Sistem yang } \\
\text { Berjalan }\end{array}$ & $\begin{array}{c}\text { Sistem yang } \\
\text { Diusulkan }\end{array}$ \\
\hline Penyediaan & Poses pelaporan & Proses pelaporan \\
Laporan & hasil QC & hasil QC dapat \\
QC & memakan waktu & dilakukan up to \\
& yang cukup & date, membuat \\
& lama, sehingga & manajemen dapat \\
& cukup & segera \\
& menghambat & mengambil \\
& manajemen & keputusan dalam \\
& dalam & rangka \\
& mengambil & peningkatan \\
& sebuah & layanan kepada \\
& keputusan. & pelanggan. \\
\hline
\end{tabular}

\subsection{Perancangan Sistem}

Proses perancangan sistem yang digunakan dalam penelitian ini adalah Unified Modelling Language (UML), dengan menggunakan alat bantu use case diagram, activity diagram, statechart diagram dan class diagrm. 


\subsection{Pengembangan Sistem}

Metode pengembangan sistem yang digunakan pada penelitian ini menggunakan metode waterfall, metode ini merupakan metode yang banyak digunakan oleh para pengembang sistem informasi karena sifatnya terstruktur dan mudah dipahami sebagai sebuah siklus hidup klasik (classic life cycle) pengembangan sebuah sistem informasi.

Metode waterfall merupakan sebuah metode pengembangan perangkat lunak (software) yang dilakukan secara berurutan, terstruktur dan terus mengalir ke bawah (seperti air terjun) melewati fase-fase perencanaan, pemodelan, implementasi, dan pengujian [6]. Metode waterfall menggambarkan pendekatan yang sistematis dan berurutan pada pengembangan perangkat lunak, dimulai dengan spesifikasi kebutuhan pengguna lalu berlanjut melalui tahapantahapan comunication, planning, modeling, construction, serta deployment, yang diakhiri dengan dukungan pada perangkat lunak lengkap yang dihasilkan [7].

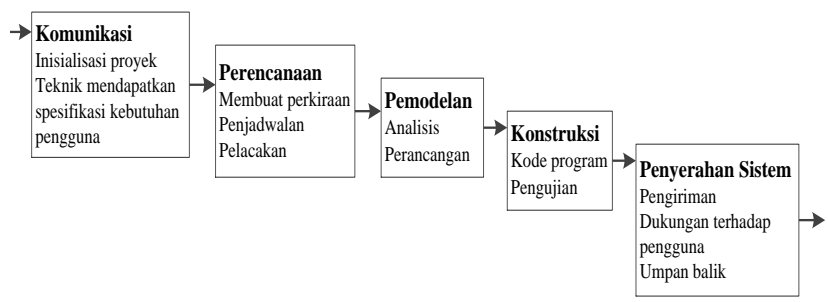

Gambar 1. Tahapan Metode Waterfall [7]

\subsection{Literatur Studi}

Sebagai referensi dalam melakukan penelitian ini, peneliti mengambil beberapa acuan dari hasil penelitian sebelumnya yang tertulis dalam jurnal berikut ini:

a. Penelitian yang dilakukan oleh Rahmayani dan Haryanto tahun 2018, yang berjudul "Rancang Bangun Aplikasi Monitoring Laporan Quality Control Dan Defective Produksi Sepatu Berbasis Web (Studi Pada PT. Panarub Industry)". Penelitian ini merupakan penelitian untuk mengembangkan proses pengelolaan manajemen data yang ada saat ini menjadi sebuah sistem yang dapat mengolah dan mengendalikan data laporan QC dalam rangka meningkatkan proses kontrol hasil produksi sepatu. Hasil penelitian, tercipta sebuah sistem yang memudahakan manajemen memonitoring laporan QC [8].

b. Penelitian yang dilakukan oleh Triono, dkk.. tahun 2018, yang berjudul "Perancangan Aplikasi Dashboard Pengelolaan Hasil Produksi Departemen Finishing Berbasis Web Pada PT Panarub Industry". Penelitian ini merupakan penelitian yang dilakukan dalam rangka membantun sebuah aplikasi dashboard data hasil produksi perusahaan. Dashboard yang dihasilkan dari data QC hasil produksi berguna sebagai data acuan manajemen dalam mengambil keputusan [9].

c. Penelitian yang dilakukan oleh Gitzel dan Maczey tahun 2015, yang berjudul "A Data Quality Dashboard for Reliability Data" Penelitian ini merupakan penelitian dalam rangka pembangunan dashboard dengan masukan data yang berkualitas untuk mengidentifikasi masalah dan memberikan saran konkret tentang tindakan pencegahan. 
Kesimpulan dari penelitian ini mengatakan dashboard hanya merupakan langkah pertama menuju terciptanya kualitas data yang lebih baik tetapi tidak berdampak pada perhitungan hasil produksi [10].

d. Penelitian yang dilakukan oleh Shui, X., et.all. tahun 2015, yang berjudul "Advanced Quality Control at Raw Material Kickoff Stage" Penelitian ini merupakan penelitian untuk membuat sebuah fungsi QC pada sebuah industri semikonduktor. Fokus penelitian ini pada penerapan kontrol kualitas canggih pada tahap kickoff bahan baku. Tujuannya adalah untuk mengurangi risiko manufaktur dengan menerapkan metodologi kontrol kualitas canggih pada tahap kickoff bahan baku dan secara ketat mengikuti persyaratan yang ditentukan selama produksi berlangsung. Penelitian ini menghasilkan kesimpulan: dibandingkan dengan metode QC bahan baku tradisional, yang berfokus pada penyelarasan spesifikasi bahan dan uji coba sampel, metode QC yang dioptimalkan dapat QC yang lebih efektif pada tahap kickoff bahan baku dan dapat mewujudkan deteksi dini bahan yang abnormal [11].

\section{HASIL DAN PEMBAHASAN}

\subsection{Use Case Diagram}

Diagram use case usulan dibawah ini menggambarkan alur kerja sistem dari awal proses penerimaan data sampai dengan proses pengecekan data. Gambar 2 menunjukkan Use Case Sistem. Table 7 berikut menjelaskan use case system yang dirancang.

\section{Tabel 7. Penjelasan Use Case}

\begin{tabular}{|c|c|c|}
\hline No & Aktor & Penjelasan \\
\hline 1 & Admin & $\begin{array}{l}\text { Pengguna yang bertugas } \\
\text { untuk mengelola data } \\
\text { barang, data komponen, data } \\
\text { defect, hasil printing dan } \\
\text { emboss, melakukan } \\
\text { monitoring hasil produksi, } \\
\text { membuat laporan } \\
\text { rekapitulasi hasil QC } \\
\text { termasuk printing, emboss. }\end{array}$ \\
\hline 2 & Manager & $\begin{array}{l}\text { Pengguna yang dapat } \\
\text { melihat laporan hasil QC } \\
\text { yang dihasilkan sistem. }\end{array}$ \\
\hline
\end{tabular}

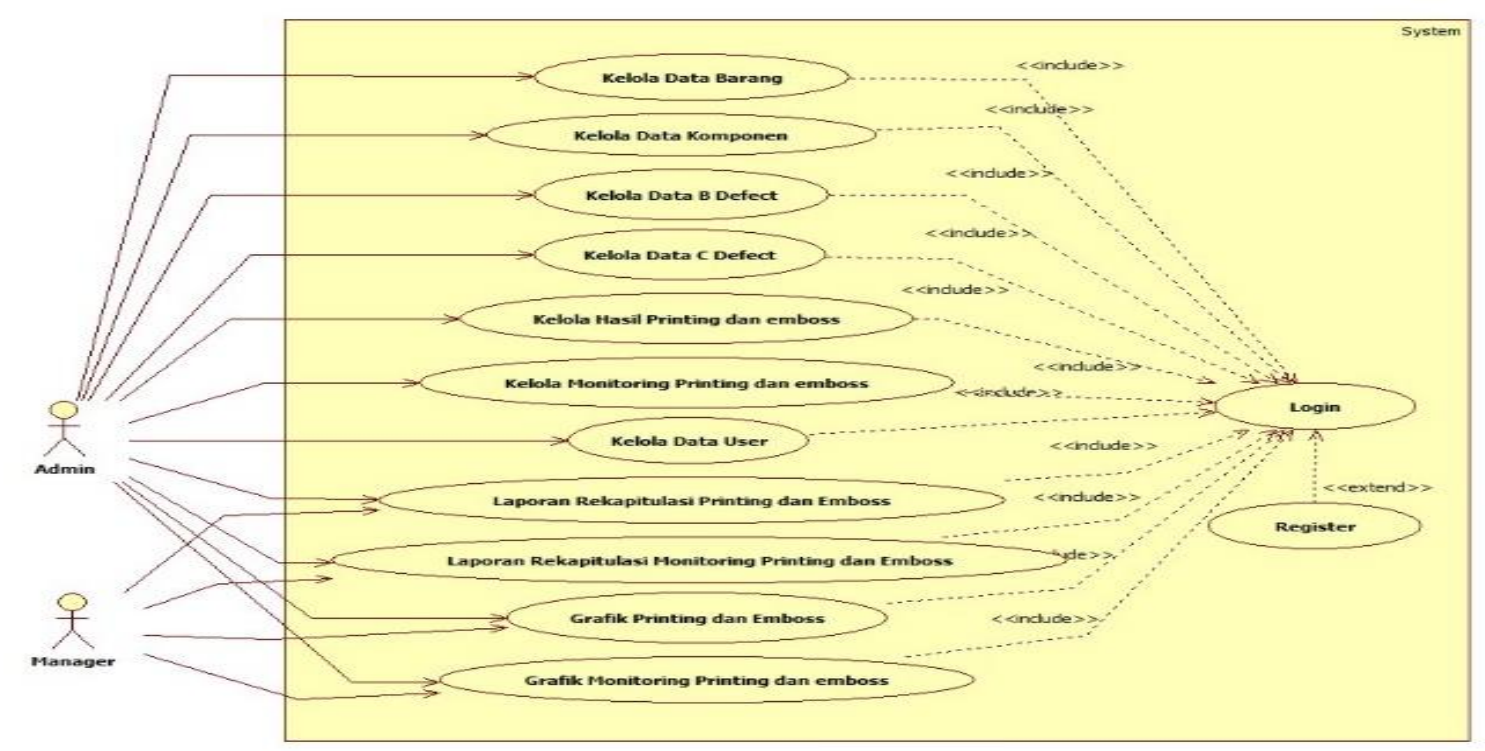

Gambar 2. Use Case Sistem yang Diusulkan 


\subsection{Activity Diagram}

Activity Diagram merupakan sebuah proses kerja dan aktifitas yang dilakukan oleh gambar worlflow (aliran kerja) dari sebuah seorang aktor dalam sebuah sistem.

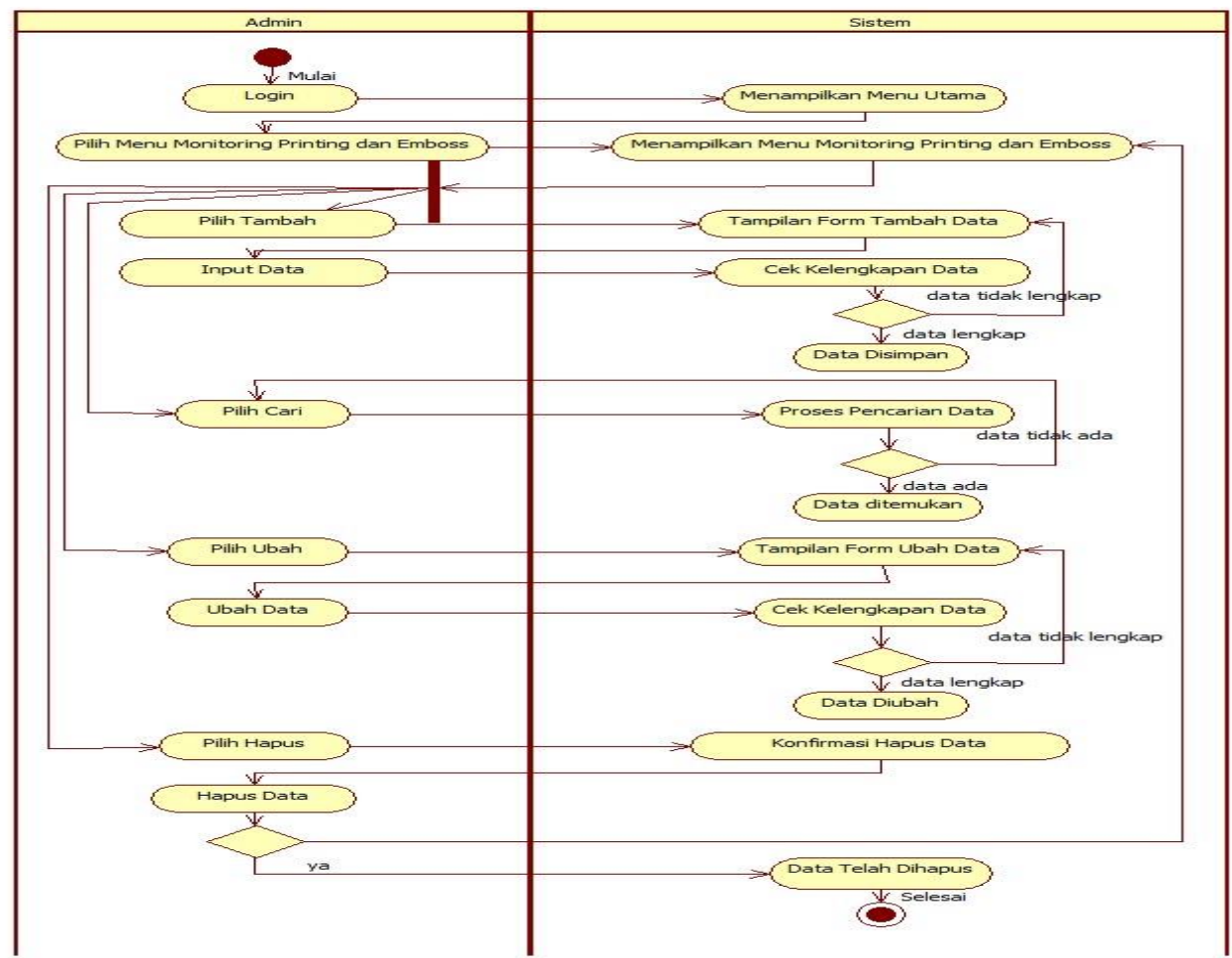

Gambar 3. Activity Diagram Monitoring Printing dan Emboss

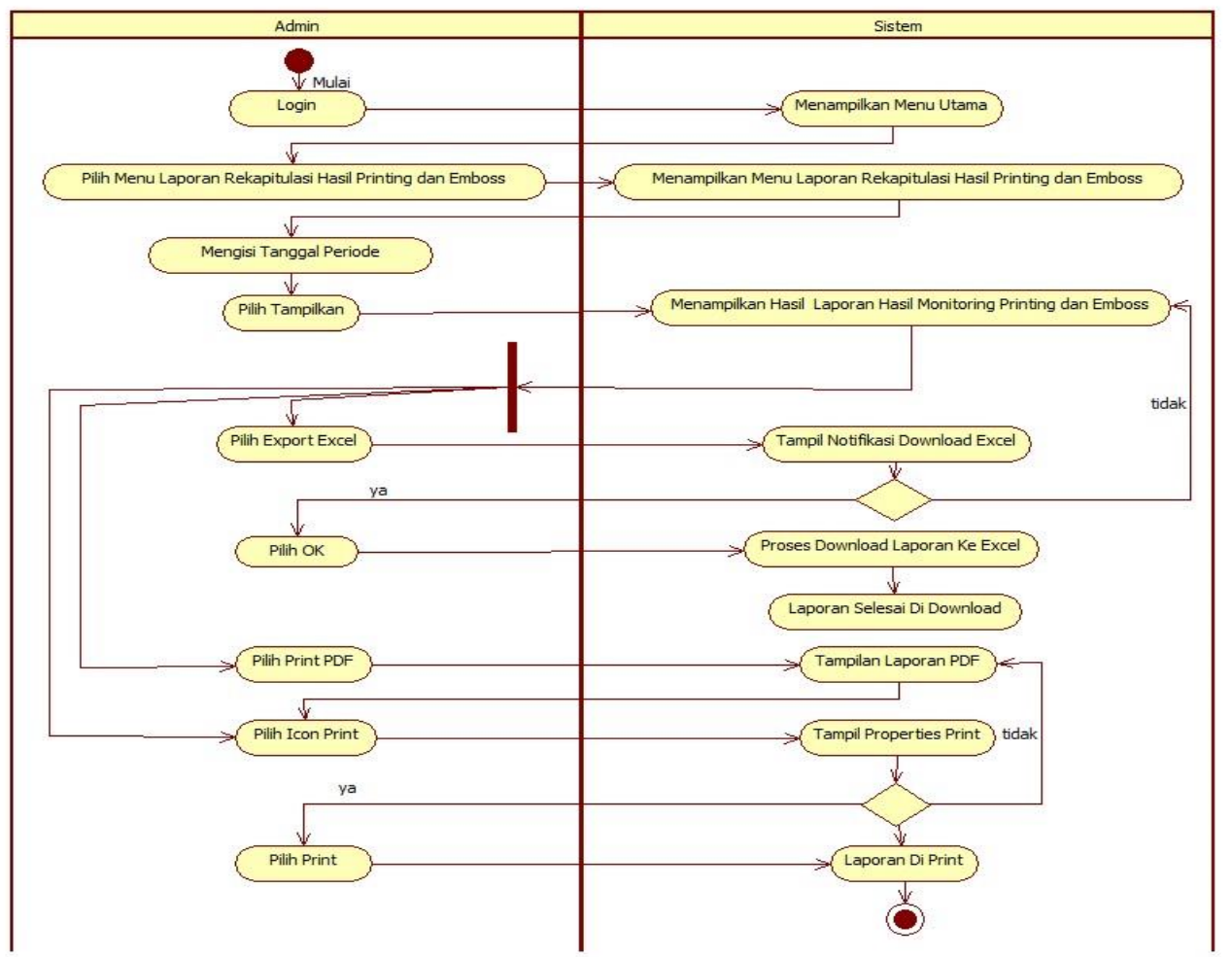

Gambar 4. Activity Diagram Laporan Rekapitulasi Hasil Printing dan Emboss 


\subsection{Statecart Diagram}

Diagram status atau statechart diagram menunjukkan kondisi yang mungkin dialami terjadi pada sebuah objek dalam sistem yang menyebabkan setiap objek memiliki sebuah diagram status. Diagram status diilustrasikan sebagai sebuah penggambaran kondisi mesin status (state machine) yang mengilustrasikan status apa saja yang dialami oleh mesin tersebut. Diagram Status mengambarkan seluruh state yang memungkinkan obyek-obyek yang adada dalam class dapat dimiliki dan segala kajadian yang menyebabkan sebuah status berubah. Pada diagram ini, dapat ditunjukan jalannya alur proses dari sebuah sistem informasi yang dikembangkan.

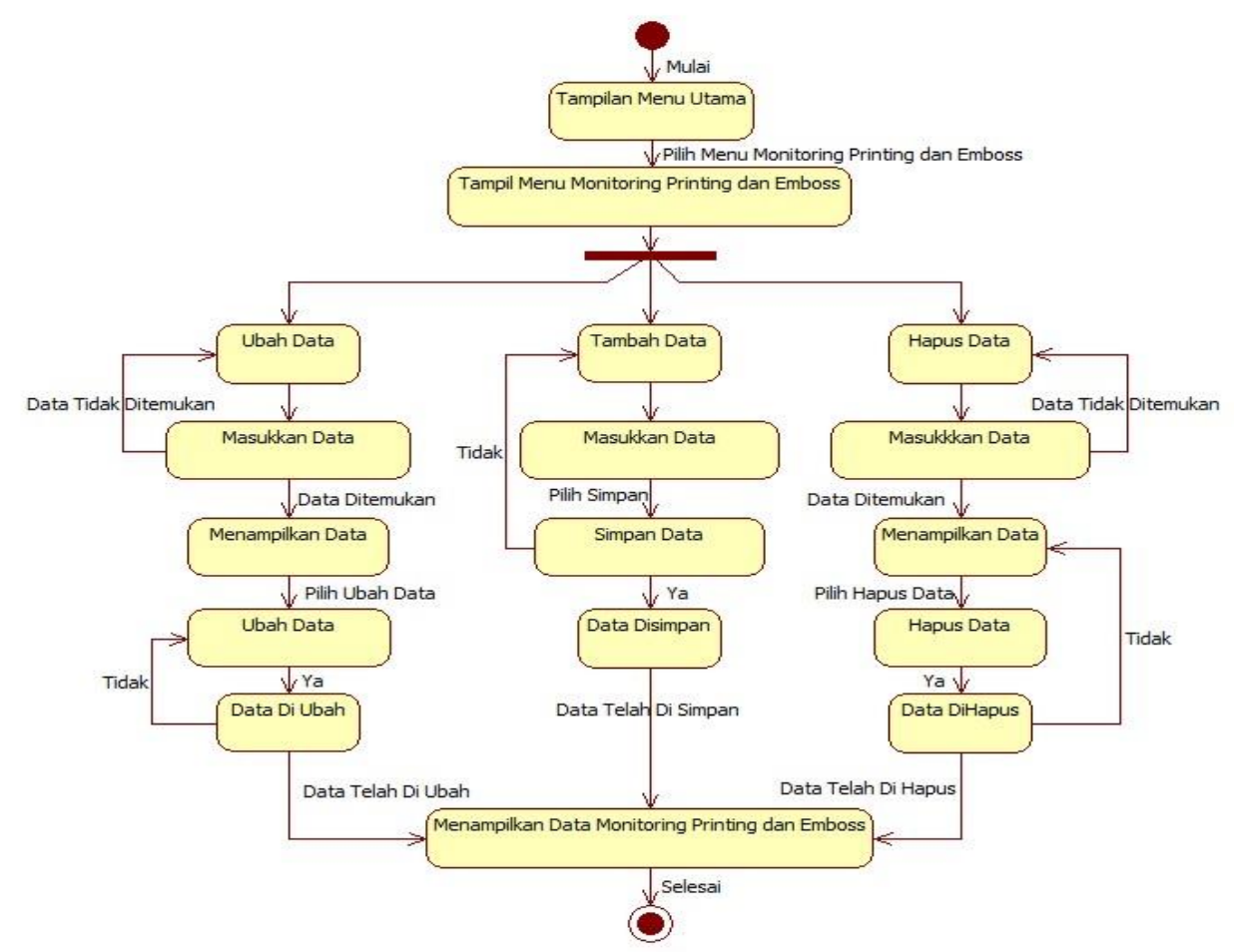

Gambar 5. Statechart diagram Monitoring Printing dan Emboss

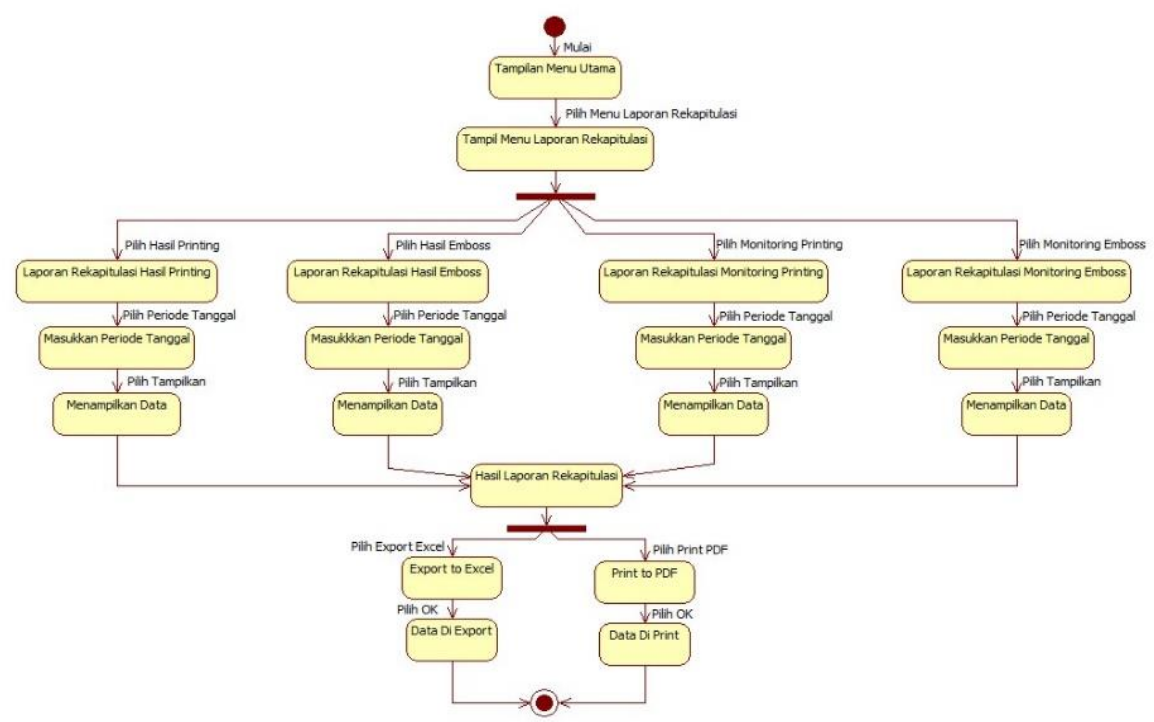

Gambar 6. Statechart diagram Laporan Rekapitulasi Hasil Printing dan Emboss 


\subsection{Sequence Diagram}

memperlihatkan komunikasi diantara objek Sequence diagram merupakan diagram tersebut.

alur yang menggambarkan interaksi objek dan

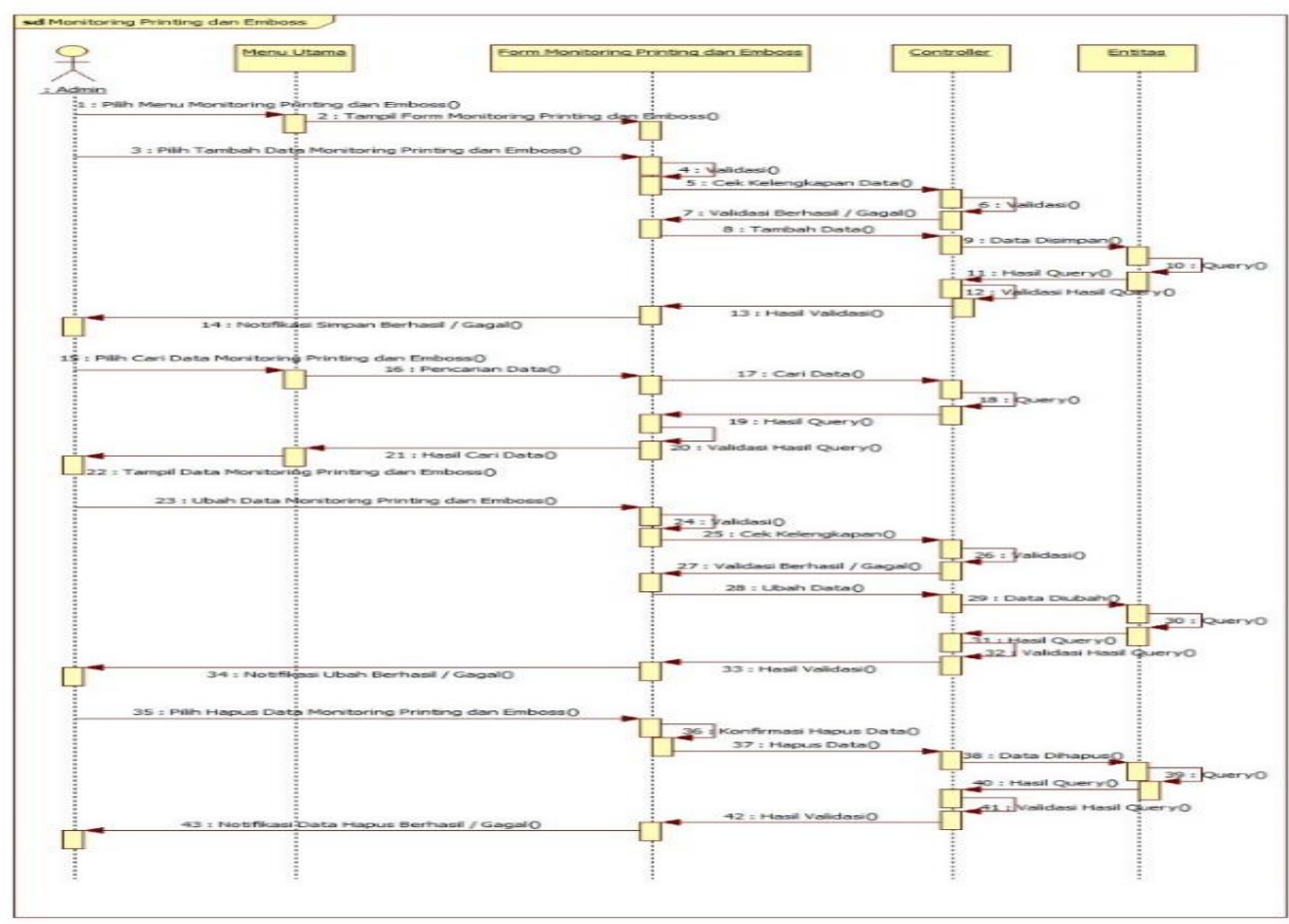

Gambar 7. Sequence diagram Monitoring Printing dan Emboss

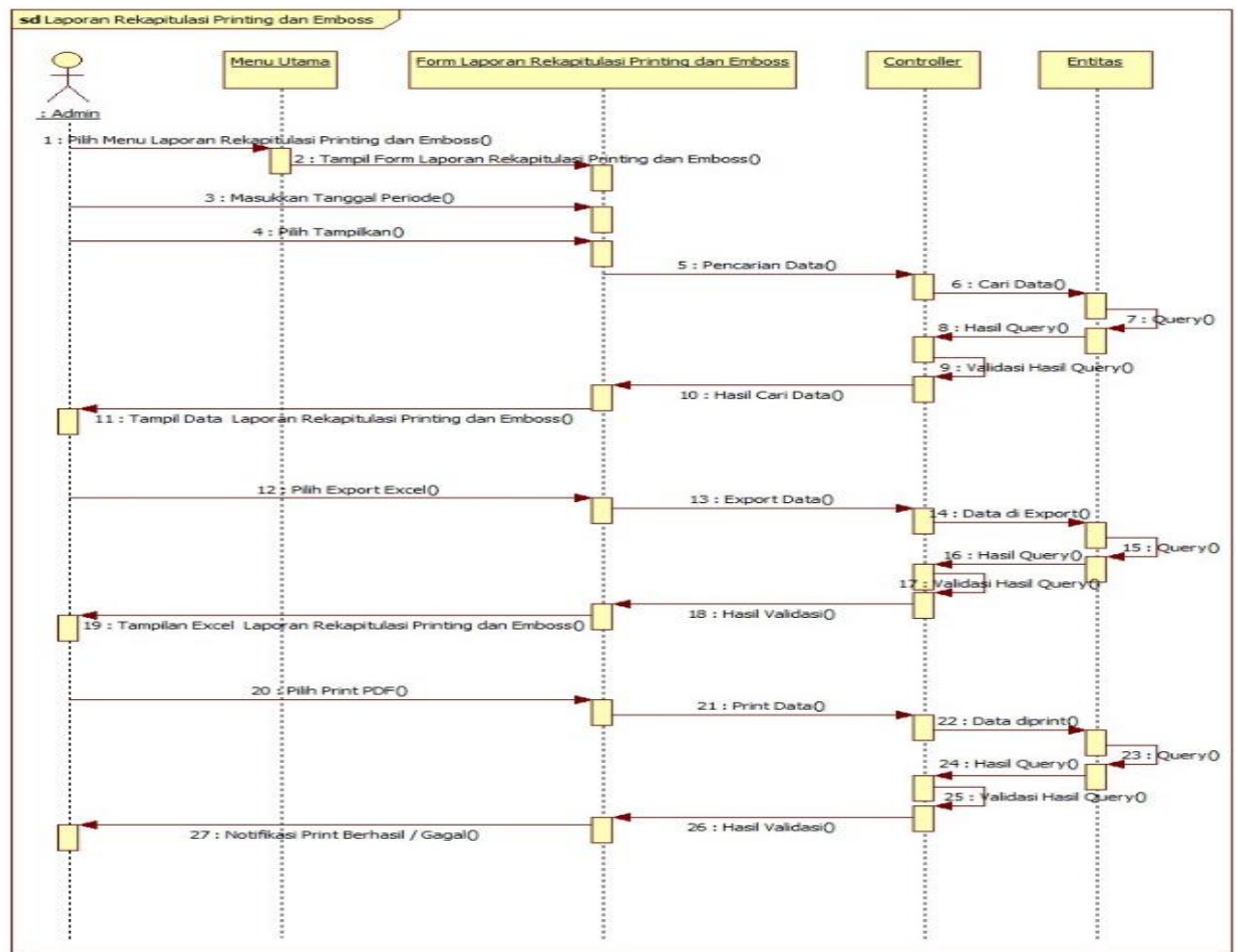

Gambar 8. Sequence diagram Laporan Rekapitulasi Hasil Printing dan Emboss 


\subsection{Class Diagram}

Class Diagram mendefinisikan kelas-kelas dan terdiri 3 bagian utama yaitu attribute, operation, dan name. yang akan dikembangkan dalam sebuah sistem,

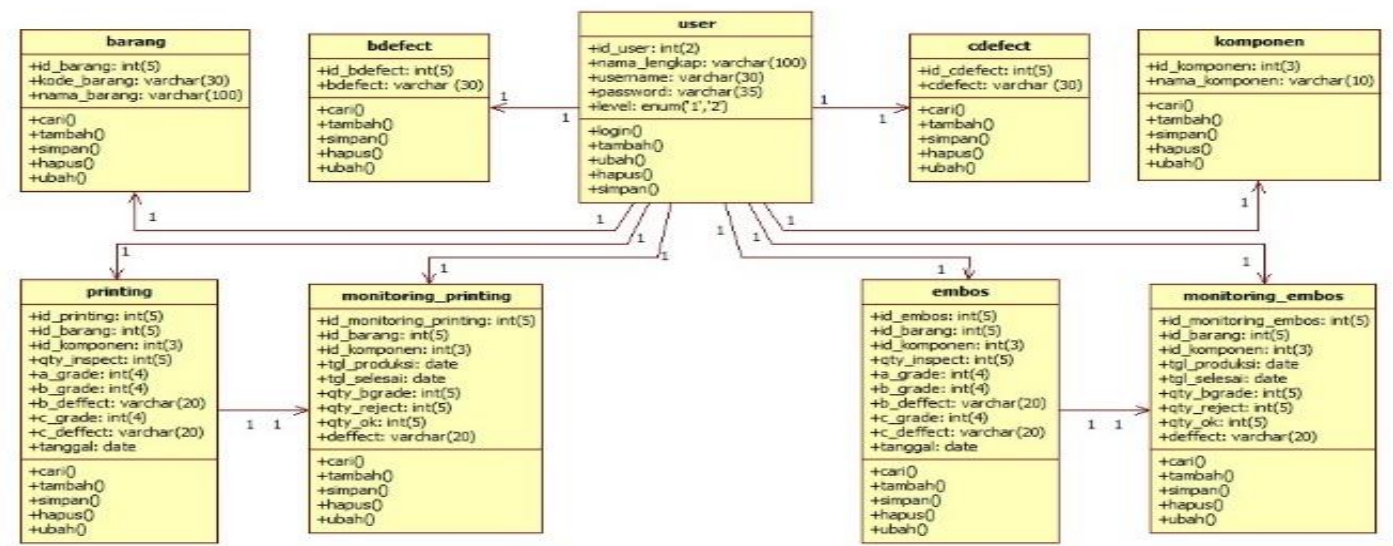

Gambar 9. Class Diagram

\subsection{Tampilan Aplikasi}

Penelitian sistem dashboard pengendalian mutu di bagian printing dan emboss pada PT. Megah Mas Prima, sebagaimana gambar tampilan muka sistem sebagai berikut:

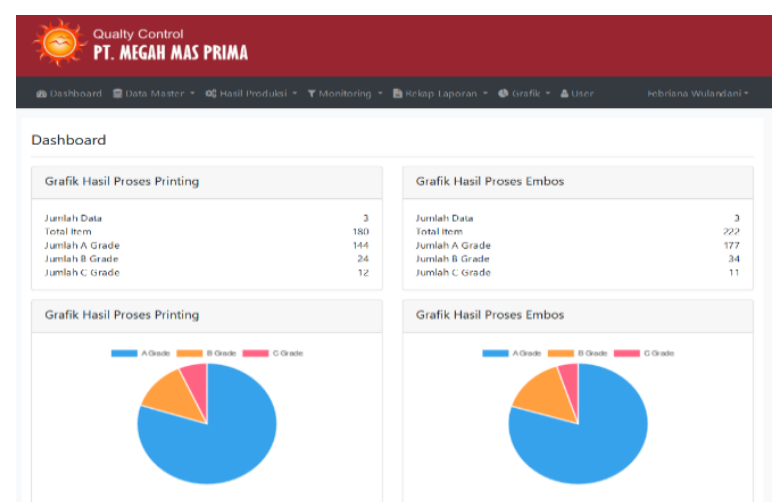

\section{Gambar 10. Tampilan Menu Utama Sistem}

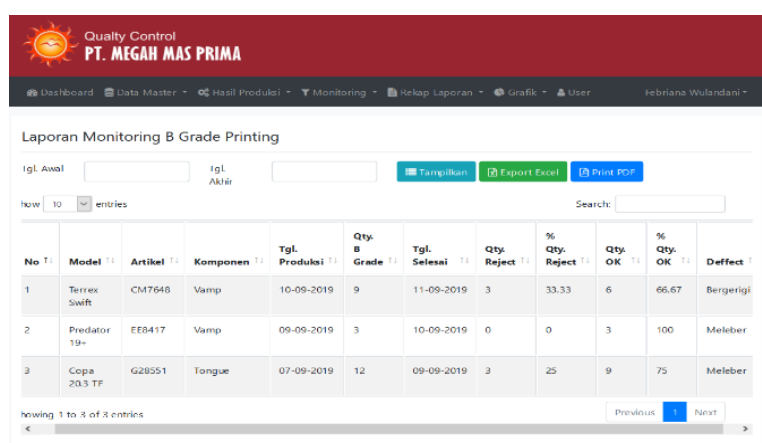

Gambar 11. Menu Monitoring QC Printing

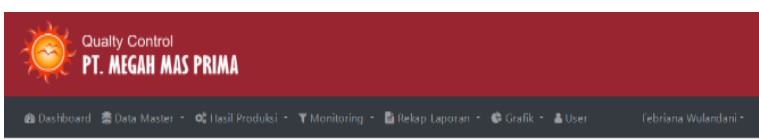

Laporan Monitoring B Grade Embos

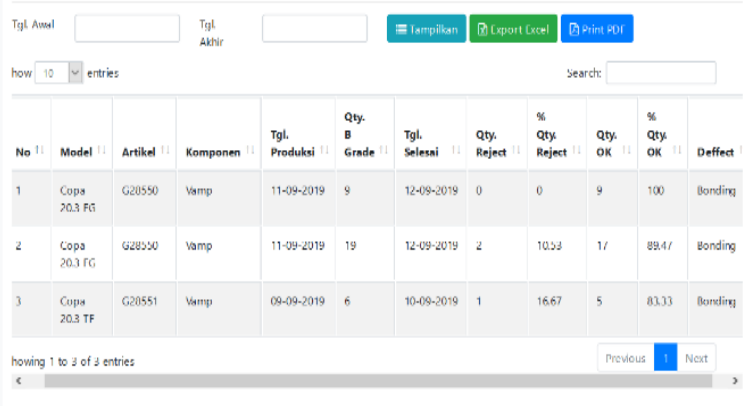

Capyigite o pr. Megain Max Prima

Gambar 9. Class Diagram
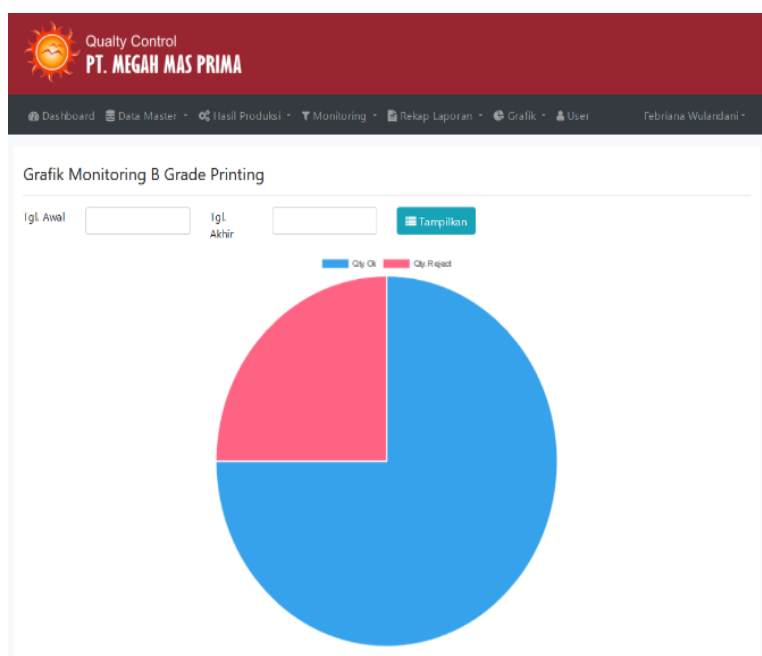

Gambar 13. Dashboard Monitoring Pengendalian Mutu Hasil Printing 

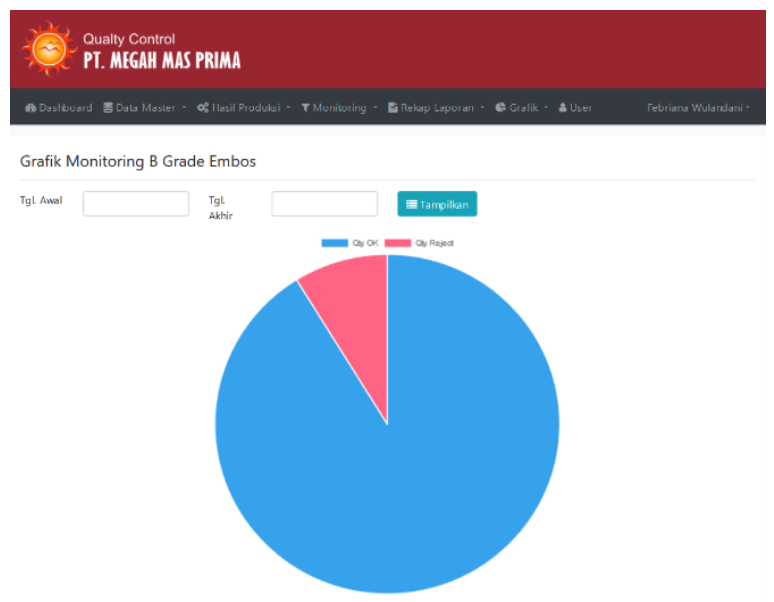

Gambar 14. Dashboard Monitoring
Pengendalian Mutu Hasil Emboss

\subsection{Uji Coba Sistem}

Sistem dashboard monitoring pengendalian mutu pada bagian printing dan emboss yang dihasilkan, diuji dengan menggunakan pengujian black box, sesuai dengan tabel pengujian berikut:

Tabel 8. Hasil Pengujian Black Box

\section{Nama Aplikasi : \\ DASHBOARD KONTROL PENGENDALIAN MUTU PADA BAGIAN PRINTING DAN EMBOSS}

\begin{tabular}{lcl}
\hline No & $\begin{array}{c}\text { Halaman } \\
\text { Yang Diuji }\end{array}$ & \multicolumn{1}{c}{ Aksi Aktor } \\
\hline 1. & Log in Admin & $\begin{array}{l}\text { Memasukkan username } \\
\text { dan/atau password } \\
\text { dengan benar dan/atau } \\
\text { salah }\end{array}$
\end{tabular}

2. Log out

3. Ubah password

4. Data barang dan komponen

5. Data printing dan emboss hasil produksi
Pilih menu $\log$ out

Mengubah password

Menambahkan data dengan memasukkan semua data barang dan komponen Mengubah data barang dan komponen yang diinginkan Menghapus data barang dan komponen yang diinginkan Menambahkan data printing dan emboss hasil produksi Mengubah data $b$ printing dan emboss hasil produksi sesuai perubahan yang perlu. Menghapus data $b$ printing dan emboss hasil produksi

Tanggal

Pengujian: 4 November 2019

Penguji: Ibu Fitri Fahyuni dan Febriana Wulan

\begin{tabular}{lrl}
\multicolumn{2}{c}{ Reaksi Sistem } & Hasil
\end{tabular}

username dan username dan/atau

password benar, maka masuk ke password salah, Sesuai harapan halaman utama admin tidak masuk ke halaman utama admin

Melakukan log out dan menampilkan halaman awal Password berhasil diubah

Data barang dan komponen bertambah

Data barang dan komponen berhasil disimpan

Data barang dan komponen akan terhapus

Data printing dan emboss hasil produksi bertambah Data printing dan emboss hasil produksi berhasil disimpan

Data printing dan emboss hasil produksi akan terhapus
Tidak melakukan $\log$ out

Sesuai harapan (valid)

Password tidak berhasil diubah Menampilkan pesan kesalahan jika ada data yang tidak diisi

Menampilkan pesan kesalahan jika ada data yang tidak diisi Data barang dan komponen tidak terhapus

Menampilkan pesan kesalahan jika ada data yang tidak diisi Menampilkan pesan kesalahan jika ada data yang tidak diisi

Data printing dan emboss tidak terhapus
Sesuai harapan (valid) Sesuai harapan (valid)

Sesuai harapan (valid)

Sesuai harapan (valid)

Sesuai harapan (valid)

Sesuai harapan (valid)

Sesuai harapan (valid) 
6. Data
B Defect dan
C Defect

7. Dashboard

kontrol pengendalian mutu printing

8. Dashboard

kontrol pengendalian mutu printing

Menambahkan data b
defect dan c defect
hasil produksi
Mengubah data b
defect dan c defect
hasil produksi sesuai
perubahan yang perlu.
Menghapus data b
defect dan c defect
hasil produksi
Memesukan periode
Dashboard kontrol
pengendalian mutu
printing
Data Dashboard
kontrol pengendalian
mutu emboss dapat
ditampilkan

Menambahkan data $\mathrm{b}$

Data b defect dan c defect hasil produksi bertambah Data $\mathrm{b}$ defect dan $\mathrm{c}$ defect hasil produksi berhasil disimpan

Data $\mathrm{b}$ defect dan $\mathrm{c}$ defect hasil produksi akan terhapus

Data Dashboard

kontrol pengendalian mutu printing dapat ditampilkan

Data Dashboard

kontrol pengendalian mutu emboss dapat ditampilkan
Menampilkan pesan kesalahan jika ada data yang tidak diisi

Sesuai harapan (valid) Menampilkan pesan kesalahan jika ada data yang tidak diisi

Data $\mathrm{b}$ defect dan $\mathrm{c}$ defect tidak terhapus

Data Dashboard kontrol pengendalian mutu printing tidak dapat ditampilkan Data Dashboard kontrol pengendalian mutu emboss tidak dapat ditampilkan
Sesuai harapan (valid)

Sesuai harapan (valid)

Sesuai harapan (valid)

Sesuai harapan (valid)

\section{KESIMPULAN}

Penelitian ini telah menghasilkan sistem dashboard kontrol pengendalian mutu pada bagian printing dan emboss, sesuai dengan kebutuhan pengguna dan telah dapat memberikan beberapa manfaat, antara lain:

1. Sistem yang dikembangkan pada penelitian ini, telah membantu memproses pengolahan data hasil produksi sebagai data masukan Pengendalian mutu untuk laporan QC khususnya QC printing dan emboss .

2. Sistem yang dikembangkan membuat data hasil laporan QC dapat diproses lebih cepat dan mudah diakses, bahkan laporan juga dapat ditampilkan dalam bentuk dashboard yang memudakan pengguna dan manajemen melakukan analisa terhadap laporan yang dihasilkan.

Saran pengembangan sistem dari hasil penelitian yang dapat penulisa sampaikan antara adalah perlu ditambahkan fitur yang dapat melakukan backup data dengan agar jika terjadi error pada server data yang tersimpan dalam database dapat diselamatkan.

\section{UCAPAN TERIMA KASIH}

Penulis mengucapkan terima kasih kepada Ibu Fitri Fahyuni selaku Section Head Quality Control bagian printing dan emboss PT. Megah Mas Prima, yang telah memberi ijin dan informasi yang peneliti butuhkan.

\section{DAFTAR PUSTAKA}

[1] Kotler, Philip. 2015. Manajemen Pemasaran, Edisi 11, Jakarta: PT Indeks, Jakarta. pp. 57.

[2] Gasperz, V. 2015. Total Quality Manajemen. Jakarta: PT Gramedia Pustaka Utama

[3] Hartono, B. 2013. Sistem Informasi Manajemen Berbasis Komputer. Jakarta: Rineka Cipta. pp. 9.

[4] Rusdiana., Irfan, M., 2014, Sistem Informasi Manajemen. Bandung, CV Pustaka Setia. pp. 32.

[5] Sudaryono, 2015, Metodologi Riset di Bidang IT: Panduan Praktis, Teori dan Contoh Kasus. Yogyakarta, Andi Offset. pp. 28. 
[6] Soleh., Dewi, A.M., Arfiah., Asdin., 2013, Metode Peninjauan Dashboard Dari Business Inteligence Untuk membuat Keptusan Lebih Baik. Prosiding Seminar Nasional Teknologi Informasi dan Multimedia. STMIK Amikom, Yogyakarta. pp. $13-18$.

[7] Pressman, S Roger. 2012. Software Engineering: A Practitioner's Approach, 7th ed. Dialihbahasakan oleh Nugroho, Adi, et.al. Yogyakarta: ANDI. pp.46.

[8] Rahmayani, L., Haryanto. 2018. Rancang Bangun Aplikasi Monitoring Laporan Quality Control Dan Defective Produksi Sepatu Berbasis Web (Studi Pada Pt. Panarub Industry). Jurnal JUTIS Vol. 6 No. 2 Bulan Nopember, Universitas Islam Syekh-Yusuf Tangerang, pp 76- 81.

[9] Triono., Zainul Hakim, Z., Amelia, R. 2018. Perancangan Aplikasi Dashboard Pengelolaan Hasil Produksi Departemen Finishing Berbasis Web Pada PT Panarub Industry. JURNAL SISFOTEK GLOBAL, Vol 8, No 2, Bulan September, STMIK Bina Sarana Global, pp. 84 - 89.

[10] Gitze, R., Turrin, S., Maczey, S. 2015. A Data Quality Dashboard for Reliability Data. IEEE 17th Conference on Business Informatics, pp. 90 - 97.

[11] Shui, X., Shangguan, A., Yu, Y., Gao, H. 2015. Advanced Quality Control at Raw Material Kickoff Stage. IEEE Journal, IEEE International Conference on Industrial Engineering and Engineering Management (IEEM), Singapore, pp. 943 -946 . 